\title{
Is willingness to contribute for environmental protection in Sweden affected by social capital?
}

\section{George Marbuah ${ }^{1}$}

Received: 5 September 2017 / Accepted: 16 January 2019 / Published online: 12 February 2019

(c) The Author(s) 2019

\begin{abstract}
This paper investigates the role of social capital in influencing individuals' willingness to contribute to environmental protection in Sweden. Four indices of social capital comprising social trust, institutional trust, civic participation and a composite index comprising all considered elements of social capital were constructed to analyse their respective association with individual decisions to contribute. Using data from the environment module of the 2010 International Social Survey Programme, we empirically show that all four social capital parameters are significant and robust drivers of Swedish public's willingness to contribute when the payment vehicles are increased higher prices or taxes or through lifestyle changes to protect the environment. Statistically, a significant association was observed for social trust and civic participation. Institutional trust is not significant when the payment vehicle is a reduction in the standard of living. Overall, however, the composite index of social capital is a robust predictor of likelihood to contribute irrespective of the payment vehicle.
\end{abstract}

Keywords Willingness to contribute $\cdot$ Social capital $\cdot$ Environmental protection . Ordered logistic regression $\cdot$ Sweden

JEL Classification A13 - A14 - Q50 - Q51

\section{Introduction}

The existing literature on the environment has identified and highlighted several factors that drive people to make financial contributions toward the provision of a public good such as the environment (see Mitchell and Carson 1989; Meyer and Liebe

George Marbuah

george.marbuah@slu.se

1 Department of Economics, Swedish University of Agricultural Sciences, Box 7013,

75007 Uppsala, Sweden 
2010). Individuals' willingness to contribute to the environment might be explained by a combination of socio-economic and demographic variables such as income, age, education, marital status, etc. An emerging strand of literature in environmental management has emphasised the critical role played by social capital in influencing pro-environmental attitudes (see Polyzou et al. 2011). Despite this recognition, studies in this area of research are limited but have been growing in the last few years. For example, recent evidence in the literature indicates that social capital is positively linked to willingness to contribute (WTC) for environmental goods, environmental regulation/policy and management success (see Gelissen 2007; Torgler and García-Valiñas 2007; Jones et al. 2009, 2010). ${ }^{1}$ Rupasingha et al. (2000) assert that "when social capital is present, externalities are internalised, which has the effect of eliminating or reducing the free rider problem and misuse of public goods while at the same time increasing investments in public goods".

The theory behind social capital as it relates to the environment posits that the abundance of social capital (e.g. trust among individuals or communities or social connections in voluntary organisations) facilitates information sharing since trust is connected closely to cooperation. The information shared might relate to several issues that could lead to environmental awareness and, therefore, increase the willingness to contribute to environmental preservation. Beyond information effects, social capital can also work through peer effect. The utilisation of the stock of social capital might influence an individual's environmental preferences due to reciprocity or the idea that other members with shared values (or norms) in the community will act similarly as he or she did in protecting the common good. Hence, if the common good is to make a financial commitment to authorities to improve environmental conditions, they will do so with the expectation that group members or individuals will replicate their act (see Sect. 2; Torgler and García-Valiñas 2007; Macias and Williams 2014 for more discussion).

At the level of operationalisation, social capital can be measured in several ways. It is decomposed into cognitive and structural parts (Putnam 2000). The cognitive component refers to the predisposition of individuals to act in a way which is beneficial for society, while the structural aspect the interaction among individuals (e.g. Kaasa and Parts 2008). Different constructs of trust (e.g. social and institutional) are often used to measure the cognitive part while the density of networks (formal and informal) and civic engagement are applied to construct the structural component. In this paper, we consider both conceptualisations in measuring social capital as it explains the willingness to contribute toward the environment in the literature (see Torgler and García-Valiñas 2007; Jones et al. 2009; Halkos and Jones 2012). Explicitly, we construct through principal component analysis (PCA), three sub-indices of social capital: social trust, institutional trust and civic engagement and networks. In the final analysis, we construct one composite index of social capital including the

\footnotetext{
1 Other relevant references include Polyzou et al. (2011), Meyer and Liebe (2010), Halkos and Jones (2012), Kollmann et al. (2012), Macias and Williams (2014), Yogo (2015), Pretty and Ward (2001), Pretty (2003), Pretty and Smith (2003), Jones (2010), Miller and Buys (2008), Polyzou et al. (2011).
} 
three sub-indices by utilising all available information in nine set of indicators measuring different elements of social capital.

This paper aims to empirically investigate the extent to which different social capital constructs are related to individual willingness to contribute for environmental protection in Sweden. We make no causal ${ }^{2}$ inference in this paper. The hypothesis we test is that all things equal, social capital is positively related to an individual's willingness to contribute for environmental protection. Ordered logistic estimation is applied to data obtained from the 2010 International Social Survey Programme (ISSP) on Sweden. The Swedish ISSP survey reflects a nationally representative selected sample covering individuals aged 19-79 years residing in 93 municipalities in Sweden.

We contribute to the social capital and environment nexus literature in the following ways. First, given the lack of studies with an explicit focus on modelling the link between social capital and the environment in Sweden, ${ }^{3}$ this study contributes in filling some of the gaps by illuminating new evidence on this relationship. In particular, we show why in Sweden, a country noted for pro-environmental initiatives; social capital could be a key driver in individual decisions in support of environmental sustainability. To the best of our knowledge, the only study within the Swedish context closely related to our paper is Harring and Jagers (2013). Harring and Jagers (2013) looked into whether or not trust (i.e. interpersonal and institutional trust) explain carbon dioxide $\left(\mathrm{CO}_{2}\right)$ tax payment on gasoline consumption among individuals in Sweden. The main finding is that both types of trust significantly promote carbon tax payment. Secondly, while acknowledging the interesting insights Harring and Jagers (2013) provide, we think their choice of social capital indicators is too narrow to fully help our understanding of its nexus with pro-environmental policy instruments. In this regard, we complement and extend Harring and Jagger's study by providing suggestive evidence on how different constructs of social capital (i.e. social trust, institutional trust, civic participation and aggregate social capital index) explain Swedish public's willingness to contribute toward environmental preservation via three different (payment) vehicles (i.e. higher taxes, higher prices and standard of living cuts). This approach is motivated by the argument in the literature that even though social capital in its aggregate form might influence willingness to contribute toward good environmental quality, individuals may react differently to different constituents of social capital in making decisions to sacrifice for the environment (e.g. Jones et al. 2009, 2010). Finally, our findings might be useful for environmental policy in Sweden. Paying close attention to particular features of social capital embedded in individuals and communities might enhance success in the design and implementation of environmental regulation.

The remainder of the paper proceeds as follows. Section 2 discusses the literature on the interface between social capital and WTC. The theoretical model, empirical

\footnotetext{
${ }^{2}$ Finding appropriate variable(s) to instrument for social capital in the current instance was elusive from the survey data or other comparable sources. As more data become available, future studies could address this issue in the paper in order to solve the causal weaknesses inherent in the results.

3 Sweden is noted for its pro-environmental initiatives.
} 
strategy and data issues are contained in Sect. 3. Section 4 interprets the empirical results while Sect. 5 provides a detailed discussion of the findings. Section 6 ends the paper with some concluding remarks.

\section{Social capital, WTC and collective management of resources}

We present a brief review of related literature on social capital as a concept and its relation to the willingness to contribute to the environment and the management of common pool resources in general. Even though it has been in existence for a few decades now, the concept of social capital is characterised by divergent views regarding a unique definition or mode of measurement, making it a complex and multi-dimensional concept (Jones et al. 2010). Furthermore, despite different authors defining it in different ways (Coleman 1990; Fukuyama 1995, 1997; Putnam 2000; Putnam et al. 1993 Putnam 1995), Putnam (1995)' definition elaborates on the key features of social capital when he stated that it represents "...features of social organizations such as networks, norms, and social trust that facilitate coordination and cooperation for mutual benefit". Woolcock (1998) further emphasised the importance of information and acts of reciprocity in social capital. Woolcock defines social capital as "...the information, trust, and norms of reciprocity inherent in one's social networks". The conclusion from Woolcock (1998) is that "...one would expect communities blessed with high stocks of social capital to grow faster, cleaner, wealthier, more literate, better governed, and generally happier than those with low stocks, because their members can find and keep good jobs, initiate projects serving the public interests, costlessly monitor one another's behaviour, enforce contractual agreements, and respond to citizens' concerns more promptly". Thus, four key elements of social capital have so far emerged from the literature: social trust (generalised and/or particularised trust, fairness), institutional trust, degree of social networks and civic participation (individual or group) and compliance with social norms (Coleman 1990; Putnam et al. 1993; Putnam 1995; Woolcock 1998).

On the relationship between pro-environmental attitudes and social capital, the literature suggests that individuals and communities endowed with high stocks of social capital tend to work together through cooperation for the benefit of the environment (Pretty and Ward 2001; Pretty 2003; Jones et al. 2009). Social trust relates to the level of trust towards other people in general or specific groups of people (Polyzou et al. 2011). Generalised trust is a key component of social trust which also influences significantly the extent to which people would obey social norms and actively (or passively) be connected to various social networks. According to Pretty (2003) and Polyzou et al. (2011), social trust shapes people's perception and expectation that other people would act similarly (e.g. comply with environmental regulation) to achieve a common good for the society. Thus, individuals willing to pay for the environment would significantly depend on the anticipated intention of others to do same (Polyzou et al. 2011; Macias and Williams 2014).

Secondly, WTC is also affected by the level of institutional trust (Jones et al. 2009; Macias and Williams 2014) since institutions are supposed to be the trustees and implementers of environmental regulations to ensure environmental 
sustainability. Institutional trust is defined "as the extent to which citizens have confidence in public institutions to operate in the best interest of society and its constituents" (Narayan and Cassidy 2001; Jin 2013). The state often undertakes the management and provision of public goods such as the environment and its parastatals entrusted with such responsibilities. The credibility and legitimacy of environmental policies and hence implementation success depend on the extent to which the people trust responsible institutions. The lower the level of trust in the state actor tasked with the provision of the public good, the lower the likely valuation individuals will attach to the good in question which ultimately affects their WTC toward its provision. Indeed, the issue of mistrust in institutions has been found to be one of the main reasons for citizens' protest responses and lower WTC in many environmental valuation studies (Jones et al. 2008; Polyzou et al. 2011).

Bourdieu (1986) refers to social networks and civic participation as citizens' activation in formal and informal organisations. These social networks and civic engagements generate relevant information flow concerning environmental issues which are connected to environmental awareness and behaviour (Jones et al. 2010). Thus, both forms of participation in social networks (i.e. at the individual and group level) influence an individual's tendency to engage in collective activities that preserve the environment and hence their WTC (Gelissen 2007; Jin 2013).

Compliance with social norms is a significant predictor of individual WTC similar to social trust (Jones et al. 2009, 2010). Social/environmental norms include formal and informal rules aimed at environmental protection (Coleman 1990; Jones et al. 2010). The extent to which individuals/communities would comply with these norms influences environmental behaviour. In places where there is a high level of disregard for social norms, non-compliance of environmental regulation is pervasive (Jones et al. 2009, 2010). Thus, social norms compliance will influence the functioning and effectiveness of proposed environmental policy and individuals' willingness to contribute to preserving the environment (Pretty 2003; Jones et al. 2010; Jin 2013).

While acknowledging that many natural and environmental resources are common pool resources and thus subject to destructive (in)actions, there is evidence that communities (or individuals) do and can collaborate to protect the environment as well as effectively manage natural resources in different contexts. There is a growing literature that links social to the theory of collective action with regard to natural capital management. Theoretical and empirical advancements in this line of research are attributable to Ostrom (1990), Singleton and Taylor (1992), Pretty and Ward (2001), Pretty (2003), Pretty and Smith (2003), Ostrom et al. (2002), Ostrom and Ahn (2003) and Ostrom (2009) among others. That individuals will eventually degrade the environment and or natural resources through their exploitation and use ${ }^{4}$ of collectively owned resources is well documented (see Hardin 1968). In the absence of formal rules/regulations and economic incentives, individuals tend to overconsume and underinvest in these common pool resources. But while

\footnotetext{
4 These actions are often induced by rational self-interest motives and shown through free-riding behaviours.
} 
regulations and incentives may likely provide only short-term benefits by way of behavioural changes, there is little or no evidence to show the positive effect of attitudes (Pretty et al. 2000; Pretty and Ward 2001). The reason for this is because people are likely to revert to their old environmentally-adverse practices once incentives and or formal regulations are no more enforceable (Pretty and Ward 2001).

It is by the above argument that recent literature on collective action advocates for social capital's role in the management of this type of resources. There is evidence to suggest that building the stocks of social capital embedded in relations of trust (and reciprocity), norms, network density and civic participation can shape behaviour and provide the needed solution to counteract adverse private actions in resource management (Pretty and Ward 2001). Indeed, several empirical studies have shown that social capital is capable of delivering long-term positive benefits in complementing regulations and economic incentives in collective management programmes in varying contexts (see, e.g. Ostrom 2009; Pretty and Ward 2001; Poteete et al. 2010; Carattini et al. 2015).

\section{Theory, empirical model, and data}

\subsection{Theoretical model}

We follow Yogo (2015) who modelled the link between WTC for the environment and the level of trust (a sole measure of social capital in the paper) for a prediction regarding the WTC-social capital nexus in this paper. Yogo's model is a modification of Owen and Videras' (2008) model. Owen and Videras (2008) originally developed a model that looked at the implementation of local sustainability programmes (i.e. Local Agenda 21) and linked it to the level of trust and community cooperation. We argue in our paper that social capital cannot solely be represented by generalised trust, albeit considered one of the most essential elements. Each element of social capital may influence individuals or groups differently (Jin 2013) and hence their WTC for environmental services. Accordingly, instead of representing social capital by only generalised trust, we incorporate into our model various elements of social capital to help us understand how these affect individual decisions regarding environmental protection. Even though our model is not novel since it follows Yogo (2015), it suffices to understand the theoretical link between WTC for the environment and its determinants of which social capital is considered significant.

The model is based on a simple consumer choice framework to facilitate the theoretical prediction of the specified empirical model (see Sect. 3.2). We consider an economic agent (i.e. an individual) with the possibility to choose between buying two different goods. The individual can decide to either buy more material goods at the detriment of the environment (i.e. products that lowers environmental quality) or demand less of material goods for better environmental quality. Let $z$ and $e$ be the amount of material goods and measurable quality of the environment, respectively. The preceding presents a potential trade-off in choosing an eco-friendly product (e.g. ecolabel goods) and a product with an adverse environmental effect (Yogo 2015). The consumer choice behaviour follows a Cobb-Douglas utility function: 


$$
U=U(z, e)=\varepsilon z^{\alpha} e^{1-\alpha},
$$

where $\alpha$ is the elasticity of utility of material goods and $\varepsilon$ is the residual variable that explains the individual's choice. Additionally, we assume that the price of the material good and ecological counterpart is given by $P_{z}$ and $P_{e}$, respectively.

The individual can make own decision to give up more of the material good that benefits the environment independent of what all other individuals would do. The implication is that the individual consumer does not anticipate any utility regarding better environmental quality given that the benefit to the environment accrues only if all other individuals reciprocate/cooperate or act similarly. Conversely, the individual can form an expectation that all other individuals will act in like manner as he did. Thus, he expects to gain $g$ from better environmental quality. The gain can be thought of as follows: a clean environment would mean better health outcomes leading to improved productivity and individual incomes in the form of higher wages. The above is the main point of departure of Yogo (2015) from Owen and Videras (2008) in the sense that in the former, the demand for better environmental quality may be higher in the presence of cooperation while the latter focuses on cooperation as the key ingredient for the implementation of environmental programmes.

Furthermore, let $p$ denote the probability the consumer assigns to the event that all other consumers will cooperate with him, and $M$ is the total available income to the consumer. But the likelihood of cooperation, $p$, is assumed to be directly linked to the presence of social capital, (SC) to the individual consumer. Thus, $p=p(\mathrm{SC})$, where $\frac{\partial p}{\partial \mathrm{SC}} \geq 0$. The consumer then solves the following utility maximisation problem:

$$
\begin{aligned}
& \text { Max } U=\varepsilon z^{\alpha} e^{1-\alpha} \\
& \text { s.t. } P_{z} z+P_{e} e=p(M+g)+(1-p) M .
\end{aligned}
$$

Solving the above maximisation problem (and setting $\varepsilon=1$ ) yields the following condition depicting the consumer's demand for better environmental quality:

$$
e=\frac{p(\mathrm{SC})}{P_{e}}(M+g)(1-\alpha) \text {. }
$$

Equation (3) posits that the demand for improved environmental quality, $e$ (i.e. WTC for environmental good by the individual), tends to rise with the income level of the individual. It also predicts that the higher the expected gain, the higher the demand for better environmental quality while an inverse relationship is evident regarding the demand for better environmental quality and price of the environmental good-furthermore, the demand for the environmental good increases with the utility of elasticity of the good, $\alpha$, a reflection of the preference for the environmental good. Social capital enters into our final econometric specification (Eq. 4) since we assume that the expected gain $g$ is only realised if there is cooperation which is further assumed to be positively correlated with social capital (i.e. $p($ SC)) (see Owen and Videras 2008; Yogo 2015). 


\subsection{Empirical model specification}

From Eq. (3) and its predictions, we posit the following empirical models for estimation:

$$
\begin{aligned}
\mathrm{WTC}_{i t}^{*}= & \beta_{0}+\beta_{1} \times \text { Social trust }+\beta_{2} \times \text { Institutional trust } \\
& +\beta_{3} \times \text { Civic participation }+\beta_{4} M_{i t}+\gamma X_{i t}+\varepsilon_{i t}, \\
\mathrm{WTC}_{i t}^{*}= & \alpha_{0}+\alpha_{1} \times \text { Social capital }+\alpha_{2} M_{i t}+\gamma X_{i t}+v_{i t},
\end{aligned}
$$

where $\mathrm{WTC}_{i t}^{*}$ is the unobserved or latent WTC variable by an individual $i$ for the environmental good at time $t$. It measures the difference in utility an individual derives from being willing to contribute or otherwise. $M_{i t}$ is the individual's level of income; $X_{i t}$ is a vector of other controls apart from income which influences an individual's WTC for the environment while $\varepsilon_{i t}$ and $\nu_{i t}$ are the random error terms in (4) and (5); $\beta_{0}, \beta_{1}, \beta_{2}, \beta_{3}, \beta_{4}, \alpha_{0}, \alpha_{1}, \alpha_{2}$ and $\gamma$ are parameters to be estimated. The observed response modalities to WTC can be summarised as follows:

$$
\text { WTC }= \begin{cases}1 & \text { if } \mathrm{WTC}^{*} \leq \mu_{1} \\ 2 & \text { if } \mu_{1}<\mathrm{WTC}^{*} \leq \mu_{2} \\ 3 & \text { if } \mu_{2}<\mathrm{WTC}^{*} \leq \mu_{3} \\ 4 & \text { if } \mu_{3}<\mathrm{WTC}^{*} \leq \mu_{4} \\ 5 & \text { if } \mu_{4}<\mathrm{WTC}^{*}\end{cases}
$$

where a respondent $i$ is indifferent between available alternatives $k$ and $k+1$ at respective thresholds $\mu_{k}$ of the observed categorical WTC variable. Ordered logit model corresponding to each response modality of WTC in (6) is estimated for Eqs. (4) and (5) using maximum likelihood.

All social capital constructs, as predicted by the theoretical model under Sect. 3.1 and much of the literature, are expected to impact positively on an individual's willingness to contribute for the environment (Jones et al. 2009; Polyzou et al. 2011; Halkos and Jones 2012; Yogo 2015). We also expect income to have a positive effect on WTC.

The vast empirical literature guides the choice of the set of controls in environmental valuation (e.g. see Mitchell and Carson 1989; Jones et al. 2009, 2010; Meyer and Liebe 2010; Polyzou et al. 2011; Halkos and Jones 2012; Macias and Williams 2014; Yogo 2015). Specifically, we account for the age, gender, household population, marital status, environmental concern and education of the individual respondent.

The effect of age on WTC is less predictable. On the one hand, younger individuals might be expected to show more concern for the environment than older ones. One of the reasons argued in the literature to support this relates to the assertion that younger individuals grew up in times when environmental issues have been receiving increasing attention in the media and, therefore, would want to safeguard their future from poor environmental conditions. That is to say, an additional age of the individual is expected to be negatively associated with willingness to contribute 
for environmental protection since older individuals will not be alive to enjoy the long-term benefits from environmental preservation (Whitehead 1991; Carlsson and Johansson-Stenman 2000; Torgler and García-Valiñas 2007; Franzen and Vogl 2013). On the other hand, older individuals concerned about their children's welfare may be willing to contribute to more protecting the environment. It might also be possible that younger generations are brought up with materialism and may be less inclined to contribute toward preserving the environment. Given these possibilities, we allow the effect of age to be empirically determined.

Gender, defined in this paper (i.e. male $=1$ ), is expected to predict WTC negatively. The reason is that much of the empirical literature points to the evidence that females are more concerned about the environment and hence are more willing to contribute. The female gender-WTC nexus has been attributed particularly to the different socialisation and social roles between men and women (Franzen and Vogl 2013). Women, with their role as caregivers and nurturers from a traditional and cultural gender socialisation perspective, have been found to be more cooperative toward issues that affect society and with their compassionate feeling are likely to have more concern for the preservation of life and the environment (Torgler and García-Valiñas 2007).

Furthermore, the literature is replete with evidence that increased education (formal and informal) is related positively with an individual's WTC for the environment. The more educated individual is likely to be more informed about environmental issues. An individual's knowledge on environmental issues may consequently increase the probability of their WTC for environmental protection. Examples of the positive impact of education abound in the literature (Gelissen 2007; Torgler and García-Valiñas 2007; Jones et al. 2009, 2010; Polyzou et al. 2011; Halkos and Jones 2012; Carlsson et al. 2013).

Environmental concern in the environmental and social psychology literature is suggested to be an essential driver of individual pro-environmental behaviour (see Gelissen 2007; Meyer and Liebe 2010). The lower the level of interest/concern for environmental issues, the lower the probability individuals will accept any proposed financial or other forms of sacrifice toward environmental protection in general. Thus, we expect to see higher environmental concern translating into higher WTC for the environment.

Finally, household size is expected to be negatively related to an individual's WTC for the environment. Larger households are expected to spend much of their limited budget resources on other needs than giving toward environmental protection (see Carlsson et al. 2013).

\subsection{Data sources and description}

The dataset for this paper was retrieved from the most recent survey wave addressing different aspects of the environment in the International Social Survey Programme (ISSP) conducted by the ISSP Research Group (2012) in 2010 (i.e. International Social Survey Programme: Environment III-ISSP 2010). This survey was the third in a series of cross-sectional surveys administered across 22 countries in 
1993 (excluding Sweden), 27 in 2000 and 32 in 2010, respectively. The environment module of the ISSP survey covers issues from but not limited to environmental concern, attitudes to environmental protection and preferred government measures to environmental protection. Because Sweden was not considered in the maiden edition of the survey, the 1993 edition was excluded from our analysis. The inclusion of Sweden in the second round in 2000 still did not allow us to consider that year because many questions social capital were never asked. In particular, questions related to trust in the government and related social capital indicators only featured comprehensively in the 2010 survey. The above enumerated challenges with the first two surveys, therefore, limit our study to the extent that we are unable to assess changes over time regarding WTC for the environment as it relates to social capital in Sweden.

We use three different variables to measure willingness to contribute as our dependent variable (see Franzen and Meyer 2010; Macias and Williams 2014). Specifically, we use questions relating to an individuals' WTC by paying higher taxes, prices and accept a reduction in their standard of living. The 2010 ISSP questionnaire asked specific questions relating to the following: 'How willing would you be to pay much higher taxes in order to protect the environment?'; How willing would you be to pay much higher prices in order to protect the environment?'; and 'How willing would you be to accept cuts in your standard of living in order to protect the environment?'. The response categories to these questions are measured on a 5-point Likert scale as follows: (1) Very willing; (2) Fairly willing; (3) Neither willing nor unwilling; (4) Fairly unwilling; (5) Very unwilling. We recode these responses in the reverse order for interpretation reasons.

The key explanatory variables in our model relate to elements of social capital, and the literature heavily influenced their selection on different questions used to measure the various components (Narayan and Cassidy 2001; Macias and Williams 2014; Jin and Shriar 2013; Jones et al. 2009, 2010; Polyzou et al. 2011; Halkos and Jones 2012). These questions are then used to construct a composite social capital index of social trust, institutional trust, civic participation and an overall composite index of social capital using PCA. ${ }^{5}$ Our measure of social trust includes trust in general and a question in the survey related to perceived fairness (i.e. perceived fairness between individuals). These two items among others such trust in neighbours, trust in family members, etc. are often used to construct an index of social trust in the literature (see Jones et al. 2010; Polyzou et al. 2011; Halkos and Jones 2012; Jin 2013). Only the above two questions were asked in the survey and were used. Institutional trust index was measured by a single-term trust in the government. The decision to use a single item is based on data limitation since this was the only institutional trust question asked in the survey. On the other hand, six elements of civic participation were included-whether an individual has signed a petition, donated money to an environmental organisation, engaged in an environmental protest, voted in the last general election, is a member in an environmental and a union. The PCA is also used to examine whether the three main constructs of social capital, social

\footnotetext{
${ }^{5}$ Full details of the PCA are not reported but available on request.
} 
trust, institutional trust and civic participation produce separate information in the data set. The results show that each component explains specific of the variance of the data. We, therefore, proceed to construct four indices: overall Social capital, Social trust, Institutional trust and Civic Participation. Three of them are composite indices and each of which is constructed as:

$$
S^{I}=\sum_{i} a^{I i} x^{i}
$$

for $I=$ Social capital, Social trust, Institutional trust and Civic participation; where $i=1, \ldots, 9$ social capital attributes, $a^{I i}$ are the weights, or factor loadings, applied to each of the three social capital indices - one on institutional trust, two on social trust and six civic participation attributes. The composite Social capital index includes all nine attributes. The computed normalised weights are obtained from the PCA and chosen where at least $60 \%$ of the variance is explained in each component/factor loading. We follow the OECD (2008) guideline for constructing composite indices using the results from the PCA to generate weights for the analysis. As an example, the composite index of Social capital is constructed as the weighted sum of the individual data on the different trust and civic engagement elements. Social trust, Institutional trust and Civic participation indices were constructed in the same way. The constructed indices were then standardised to range between 0 and 1 such that values close to 1 would mean very high stock of a particular type of social capital and vice versa.

We measure social trust, comprising generalised trust and fairness, based on the following questions (van Oorschot et al. 2006; Jones et al. 2009): 'Generally speaking, would you say that most people can be trusted or you can't be too careful?' The responses to the question are a 5-point Likert scale with lowest values denoting lowest trust levels (i.e. $1=$ you can't be too careful to $5=$ most people can be trusted). The second question relates to how fair people are to the individual. It reads "Generally speaking, do you think most people would try to take advantage of you if they got the chance, or would they try to be fair? Similarly, the response scale is 5-Likert with $1=$ most people would try to take advantage to $5=$ most people would try to be fair. It has been shown in the psychology literature that generalised or interpersonal trust is highly correlated with individuals' "belief in a just/fair world". This perception of other people then becomes an essential component of an individual's perceptions of fairness in society. Thus, fairness (or unfairness) of a society affects the individual's perceptions and hence their level of generalised trust (You 2012).

The following question measures institutional trust on the other hand: 'Most of the time we can trust people in government to do what is right' with corresponding response $1=$ strongly agree to $5=$ strongly disagree. Again this response category is recoded in the reverse order for ease of interpretation before using it for the PCA. We drop all responses corresponding to "Neither agree nor disagree" to reduce any biases in the results.

Civic participation, connoting the level of interest for public issues (Narayan and Cassidy 2001; Jones et al. 2009) and a proxy for social networks, is measured with six variables on a dichotomous scale (i.e. 'Yes I have $=1$ ' and 'No I have not $=0$ '). 
The questions for the above responses include: in the last 5 years, have you (1) 'given money to an environmental group?' (2) 'taken part in a protest or demonstration about an environmental issue?'; (3) 'have you taken part in a protest or demonstration about an environmental issue?'; (4) Did respondent vote in last general election? (with response yes $=1$, zero otherwise). Our final measure of civic participation is at the group or membership level on the same scale (yes $=1$ and no $=0$ ). The question regards whether or not a respondent is a member of any group with the aim of preserving or protecting the environment or a member of a trade union. Table 8 in the appendix summarises all the questions used in forming the various social capital constructs.

Environmental concern was measured by the question: "How concerned are you about environmental issues? Respondents then select responses from " $1=$ not at all concerned" to " $5=$ very concerned". Income quintiles of self-reported gross monthly personal earnings in Swedish Krona (SEK) are computed and used in this paper. The reference category is the $20 \%$ poorest income quintile. Table 1 gives a summary statistics of all the data used in the analysis.

\section{Results}

In this section, we estimate ordered logistic regressions to empirically examine the nexus between individual WTC and its association with social capital. In all cases, marginal effects of the estimated coefficients have been reported directly. This is to enable an interpretation of the results regarding how a change in each explanatory variable affects the probability of willing to contribute to the environment. Table 2 shows results for willingness to pay higher prices and how it relates to the three indices of social capital constructed from the PCA (social trust, institutional trust and civic participation). Table 3 , however, considers a composite index of social capital and its nexus with WTC. A similar analysis is made about payment of higher taxes (Tables 4, 5) and willingness to accept standard of living adjustments (Tables 6 and 7 in the appendix) to safeguard the natural environment. Of particular interest are respondents who answered they were at least "fairly willing" to contribute to preventing environmental damage and how social capital influences that decision. The reason for considering these three types of willingness to contribute indicators is to assess whether various elements of social capital are related to individuals' (proenvironmental) behaviour differently or similarly. Further, it is also a check for robustness of the results.

Key among the results we find that social capital is significantly related to individual WTC. Social and institutional trust, as well as civic participation, has the expected positive association with WTC across all estimated models. For example on social trust, the results suggest that an individual with high stocks of social this form of social capital additively increases his or her probability of being in the "very willing' to contribute toward environmental protection category by about 1.59, 2.2 and 4.68 percentage points through payment of higher prices, taxes and acceptance of living standard reductions, respectively (see Tables 2, 4, 6). Similar interpretation 


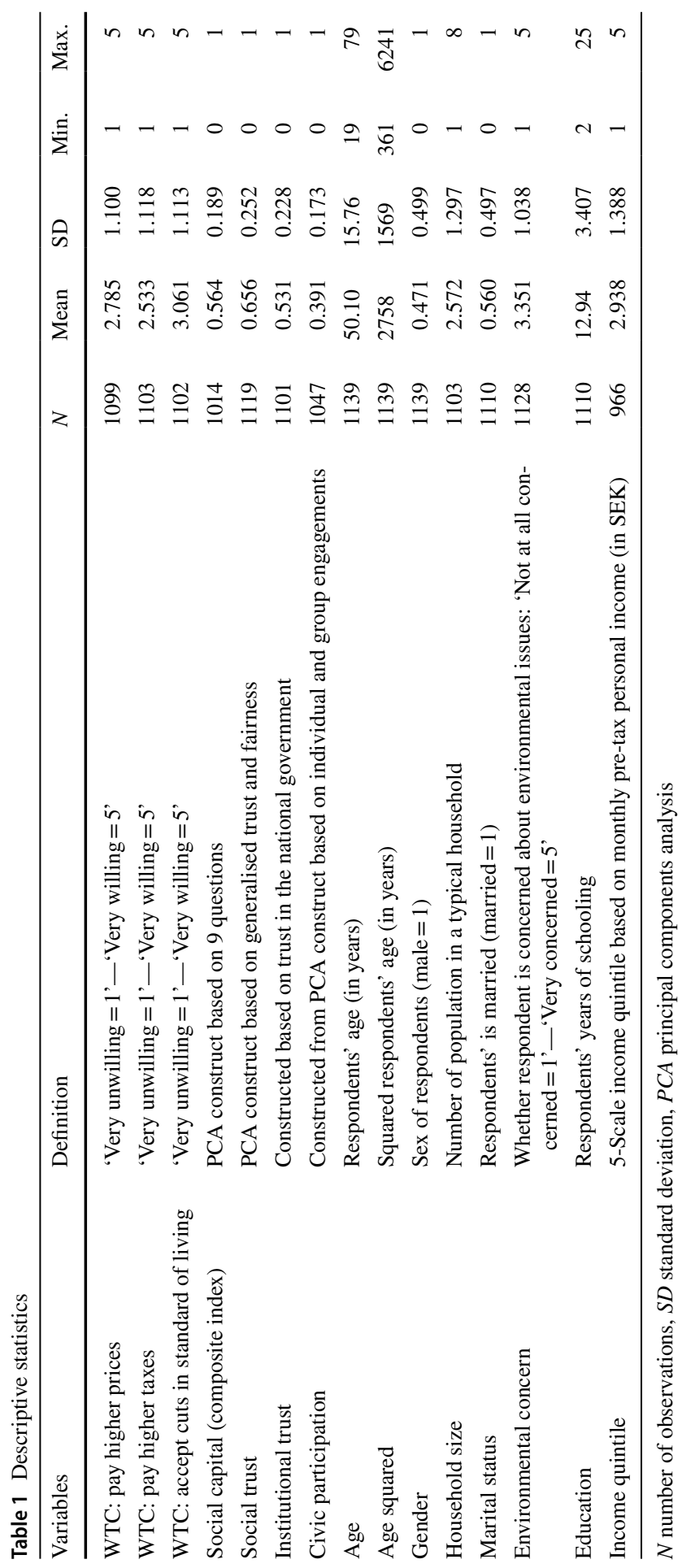




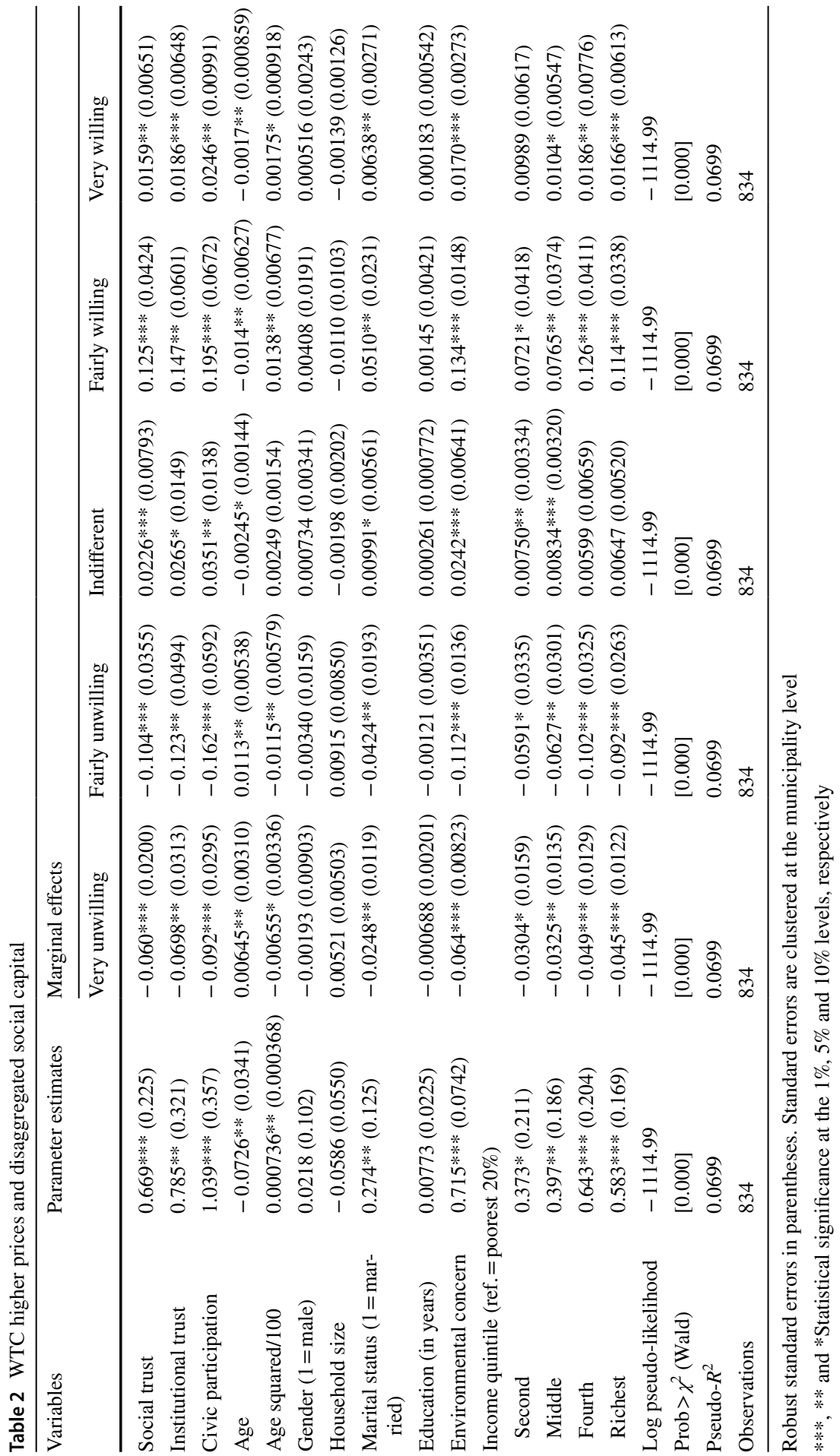




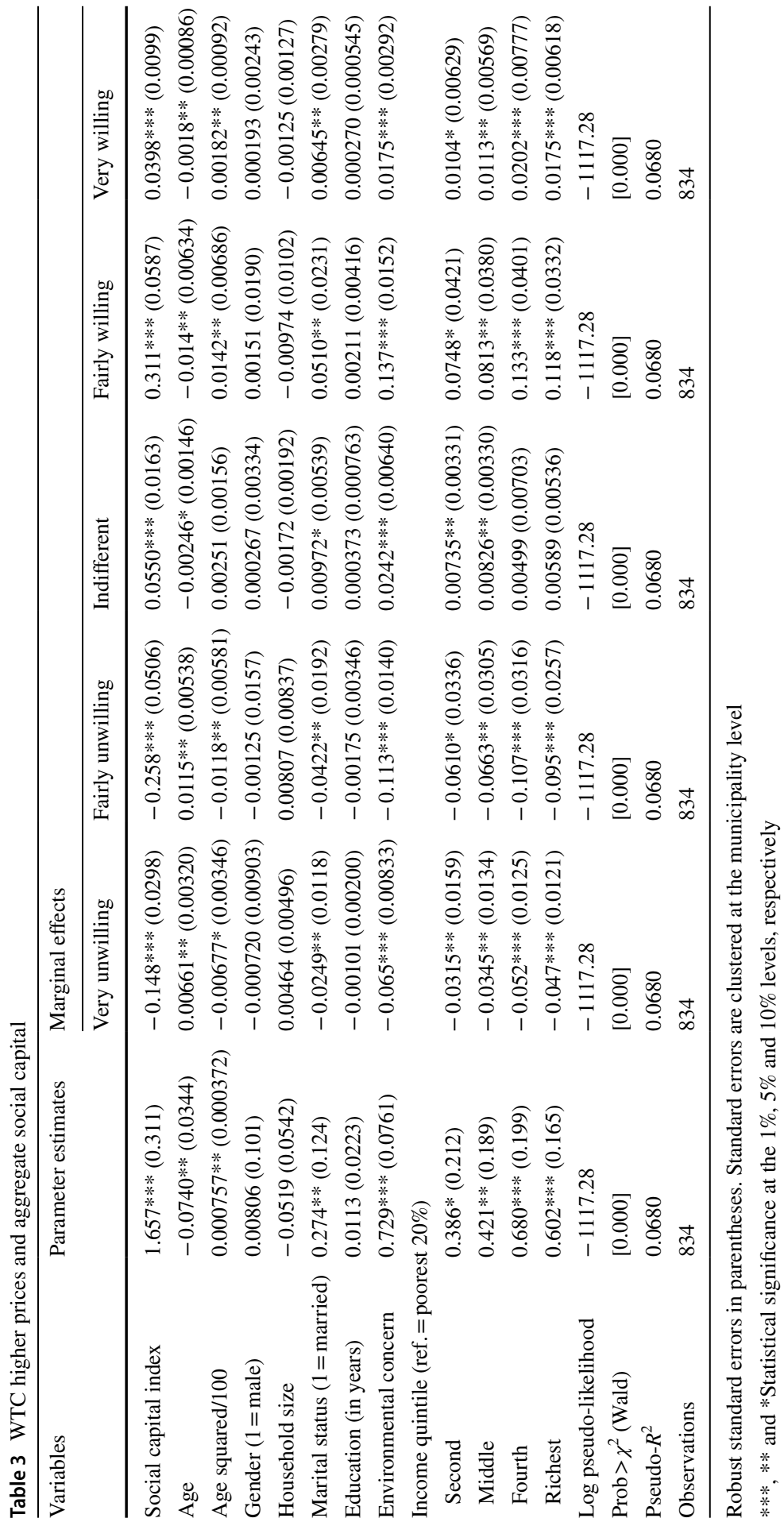




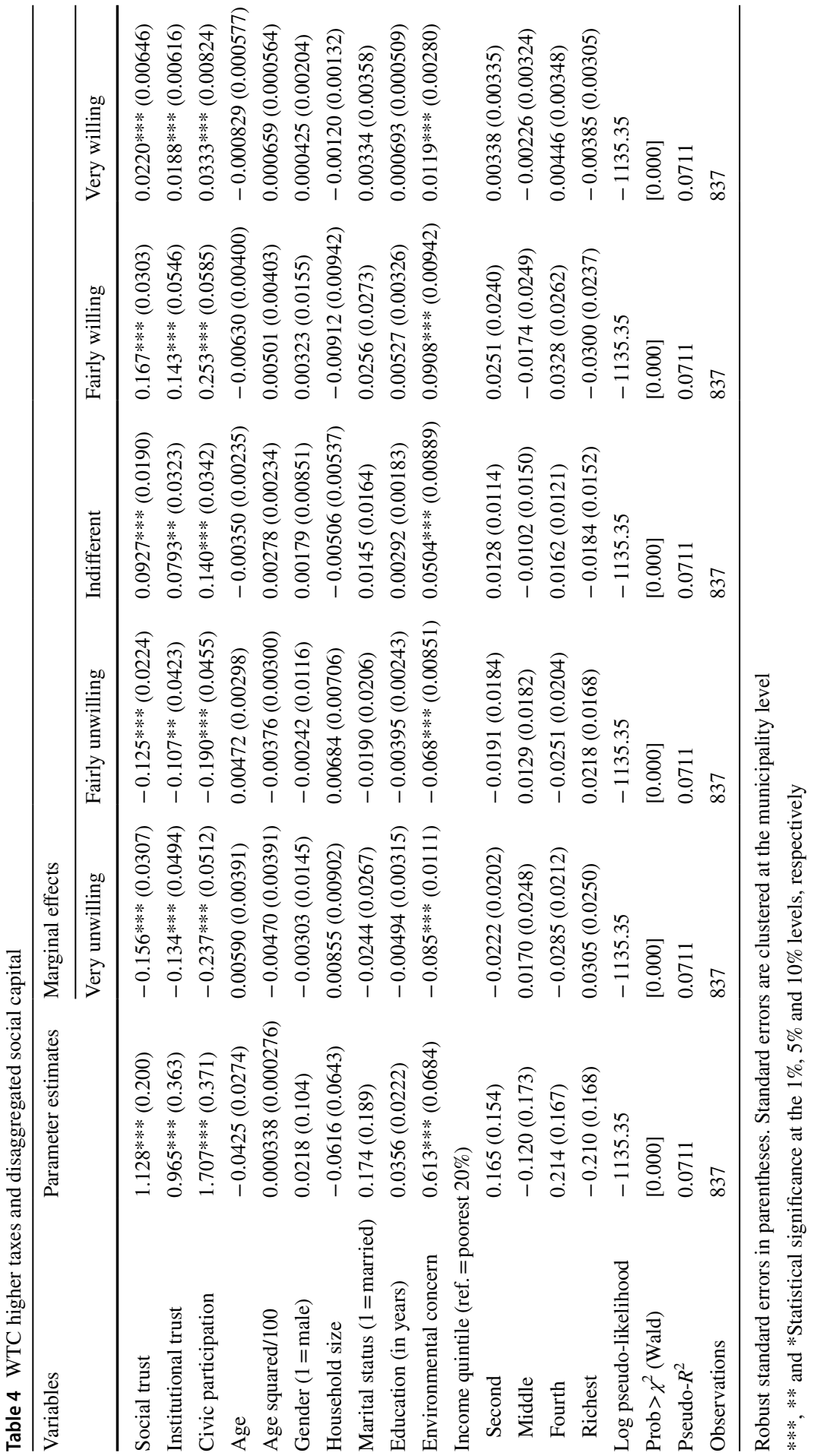




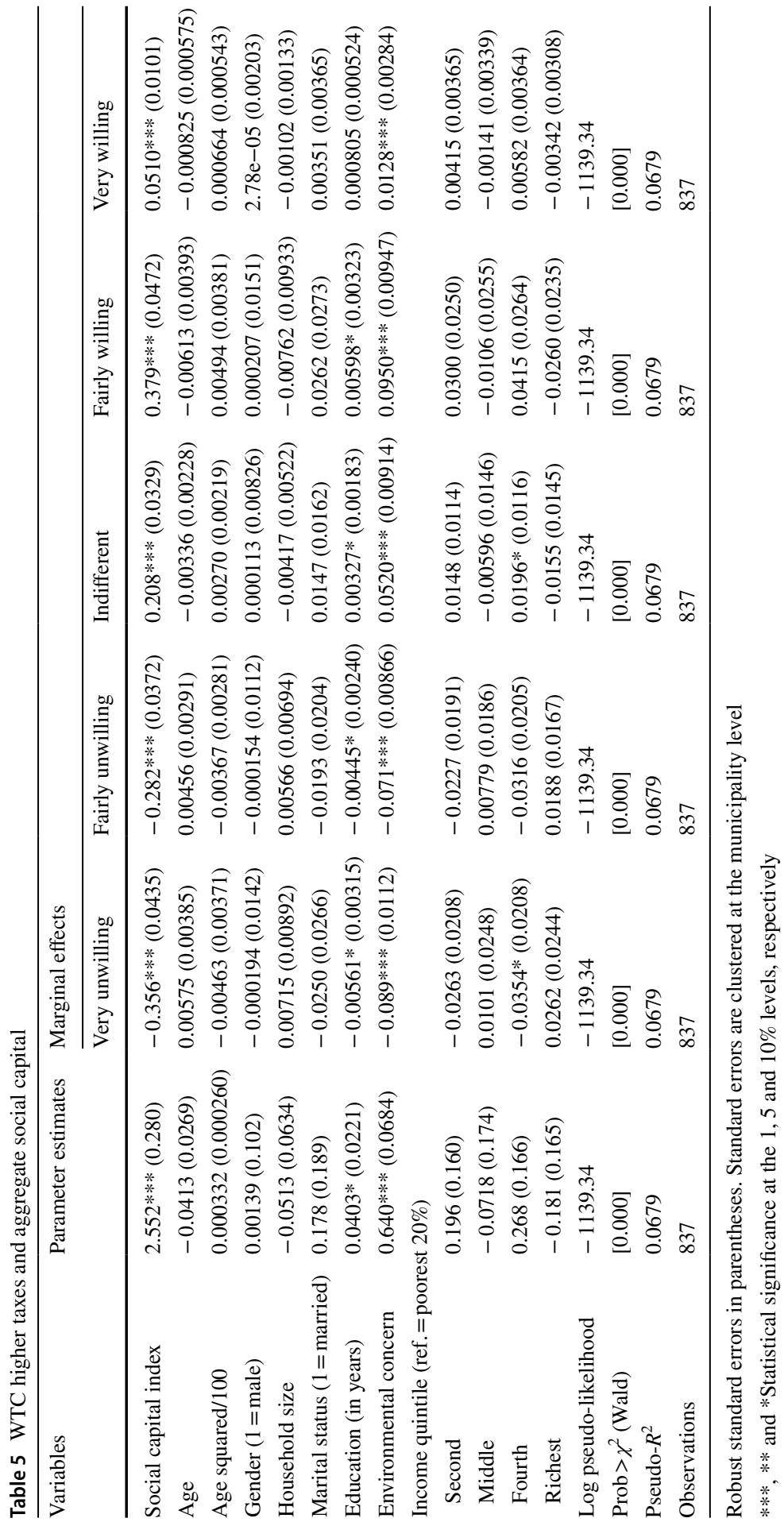


holds for all the cases. The results compare quite well with the literature (Jones et al. 2015; Macias and Williams 2014; Jones et al. 2009; Meyer and Liebe 2010).

The role of institutional trust appears significant in the determination of the public's decision to pay higher prices and environmental taxes but not standard of living albeit positive. The results in Tables 2 and 4, for instance, indicate that all other things equal, an increase in the level of institutional trust increases the likelihood to pay higher prices and environmental taxes by as much as $1.9 \%$ and $14.7 \%$. Again, this finding corroborates the evidence in the literature (see Ivanova and Tranter 2004; Halkos and Jones 2012; Macias and Williams 2014; Jones et al. 2015).

Furthermore, we find the effect of social capital to be even stronger in magnitude when we consider civic engagement and strength of social networks among respondents. The predicted probability on WTC ranges between $2.5 \%$ and $25.3 \%$ for all payment vehicle scenarios, thus confirming what is generally hypothesised and evident in the emerging literature (e.g. Torgler and García-Valiñas 2007 for Spain and the Greek evidence in Polyzou et al. 2011).

Results for the composite social capital index are unambiguous in predicting a strong and positive association with willingness to contribute toward preventing environmental damage, with the strongest prediction coming from payment of higher taxes (i.e. 38\% probability for fairly willing to pay responders—see Tables 3, 5, 7). Similar results have been shown in the literature (see Jones et al. 2009, 2010; Yogo 2015).

Finally, among the set of controls, we find marital status is not a significant predictor of WTC except for the payment of higher prices. Household size also plays no significant role in individual decisions. The coefficient of years of schooling has the expected signs but marginally significant only when social capital aggregate is considered for the payment of higher taxes. The effect of age is significant just in the case of willingness to pay higher taxes. The relation is $U$ shaped implying the young are less willing to pay more to improve environmental quality than the old. This result contrasts some evidence in the literature but compares well with a few. It is plausible to assume that the younger generation are likely preoccupied with meeting other needs of their present life than to make an additional payment for something they probably find more beneficial in the future (Yogo 2015). The results further suggest that gender is inconsequential across all models. Generally, environmental concern among the public, besides social capital, appears to be the most significant and robust driver of the probability to contribute. Higher levels of interest/concern for environmental issues translate into a higher propensity to accept proposed upward price and tax adjustments as well as making lifestyle downgrade aimed at environmental protection among the Swedish public (see Gelissen 2007; Meyer and Liebe 2010). The effect of income does not appear robust or inconsistently predict the outcomes of interest. It is generally only significant when the outcome variable is the willingness to pay higher prices. The results suggest that more affluent individuals relative to the poorest income quintile are more willing to incur additional cost to protect the environment in Sweden. The income finding is intuitive and consistent with the affluence or compensation hypothesis. This hypothesis predicts that given a constrained budget and same preferences, more wealthy individuals will be able to expand more for environmental goods than less wealthy individuals. 


\section{Discussion}

Our results provide robust evidence on the importance of various social capital indicators in shaping our understanding of the extent to which individuals in Sweden may or may not be willing to support pro-environmental initiatives. The findings show that people would be willing to make significant monetary contributions and or adjust their current or future living conditions (e.g. ride the bicycle or public transport with fossil-free biogas fuel instead of using own private car) to improve environmental quality. These social capital constructs appeared to be even more important factors and robust than well-known traditional drivers of willingness-topay (WTP) such as income, age, marital status and education. To the extent that people are very willing to support through payment of much higher taxes and prices or lifestyle changes to protect the environment, given the level of trust between the public and in state institutions and active civic participation demonstrates the fact that notable successes in the implementation of environmental regulations in Sweden over the years might have been likely fueled by these social capital factors.

Sweden is among a small number of innovative countries ${ }^{6}$ considered pace-setters in environmental policymaking with significant implementation success (Jänicke 2005). Together with the US and Japan, Sweden became a key global trendsetter of environmental regulation in the 1970s-1990s in the industrialised world (Jänicke 2005). It was among the first countries to introduce a carbon tax on gasoline in the world. In recent times, Sweden has consistently performed remarkably well in rankings on global environmental issues. In the latest report from the climate change performance index for OECD member countries, Sweden ranked tops due to low $\mathrm{CO}_{2}$ emissions level and good emission trends in especially the housing sector (Burck et al. 2012). The country was also adjudged as the most efficient of all $58 \mathrm{CO}_{2}$ emitters in 2013 with a ranking of 5th (Burck et al. 2013). In a related study, Sweden ranked 9th among 86 European countries in the Environmental Performance Index (EPI ${ }^{7}$ ) for 2014 (Hsu et al. 2014).

These successes could not have been possible only through the mere introduction of market-based policy instruments such as environmental taxes (e.g. carbon tax on gasoline). High level of trust among citizens may signal that all things equal other citizens would act pro-environmental and that people might be willing to serve the common good of their communities. Similarly, if citizens perceive the government to be less trustworthy, then the state is likely to lose policy credibility and hence support for environmental policies and programmes are likely to fail. It is a widely held view that Swedes tend to pay higher taxes to the state for different purposes including those used for improving environmental quality. This notion is likely not be the case if citizens thought politicians and state agencies would not do what is right and misuse the tax receipts or any other payment vehicle deemed appropriate. Indeed, Hammar et al. (2009) have documented evidence to the effect that in Sweden "... it is important for politicians to be perceived as trustworthy in order to be able to collect taxes for maintaining the welfare state".

\footnotetext{
${ }^{6}$ Sweden, Denmark, The Netherlands.

7 The EPI is developed at Columbia and Yale Universities and used to rank how well countries perform on high priority environmental issues within two broad policy objectives of protection of human welfare from environmental harm and protection of ecosystems. The index is developed from a comprehensive set of 20 indicators.
} 
Notwithstanding the results from this paper, there remain unresolved aspects which could be considered in the future. Since there is no universally accepted measurement of social capital, this paper had to rely on much of the literature replete with different suggestions on operationalisation of various social capital constructs. For instance, we were successful in measuring institutional trust with only a single item, a potential limitation of the paper. This was due to the lack of additional information in the survey beyond question related to trust in the government. Efforts toward a unified framework for measuring social capital are beyond this study but will be an interesting agenda to pursue going forward. To this end, it would be interesting to investigate institutional trust as it relates to actual environmental state institutions (e.g. the Swedish Environmental Protection Agency, Ministry of Environment or environmental departments/units within municipality and country administration boards) in order to gauge citizens' level of trust toward their work and how that would affect their decision to support policies and programmes that benefit the environment. Finally, since the ISSP survey did not ask actual monetary valuation questions, further studies in this regard and its relationship to social capital are worth considering.

\section{Conclusions}

The main aim of this paper is to assess whether various elements of social capital influence individuals' decision to contribute either financially or through a standard of living adjustment to preserve the environment. Using the latest survey data from the International Social Survey Programme (ISSP) on the environment and focusing on Sweden as a case study, we show that social capital measured as an aggregated index and sub-indices (social trust, institutional trust and civic participation) is significantly associated with willingness to contribute for the provision of environmental goods. The results are robust to the measure of willingness to contribute (i.e. payment of higher prices, taxes and approval of standard living reductions) and individual-level controls. These findings complement the literature on the importance of social capital variables as a conduit for enhanced collective action and management of environmental resources including quality improvements.

From the preceding, it is plausible to cautiously conclude, given the fact that we are unable to causally estimate impact in this paper that social capital, measured and operationalised in different ways, might be an essential driver of citizens' valuation for the provision of pure public goods (e.g. environmental goods). This, in turn, will likely affect their willingness to contribute to the provision of essential environmental goods in Sweden regardless of the payment vehicle considered.

Open Access This article is distributed under the terms of the Creative Commons Attribution 4.0 International License (http://creativecommons.org/licenses/by/4.0/), which permits unrestricted use, distribution, and reproduction in any medium, provided you give appropriate credit to the original author(s) and the source, provide a link to the Creative Commons license, and indicate if changes were made.

\section{Appendix}

See Tables 6, 7 and 8. 


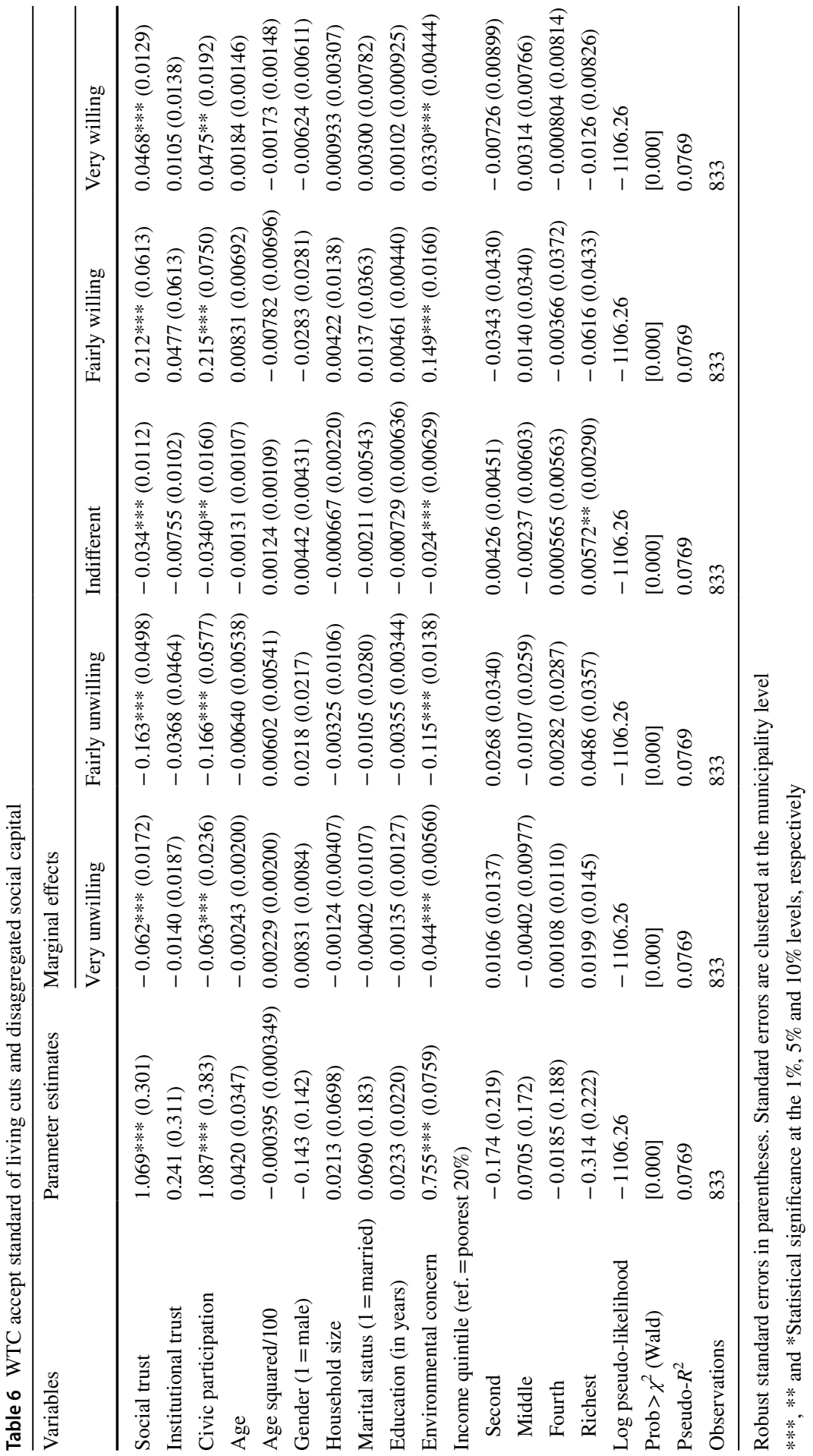




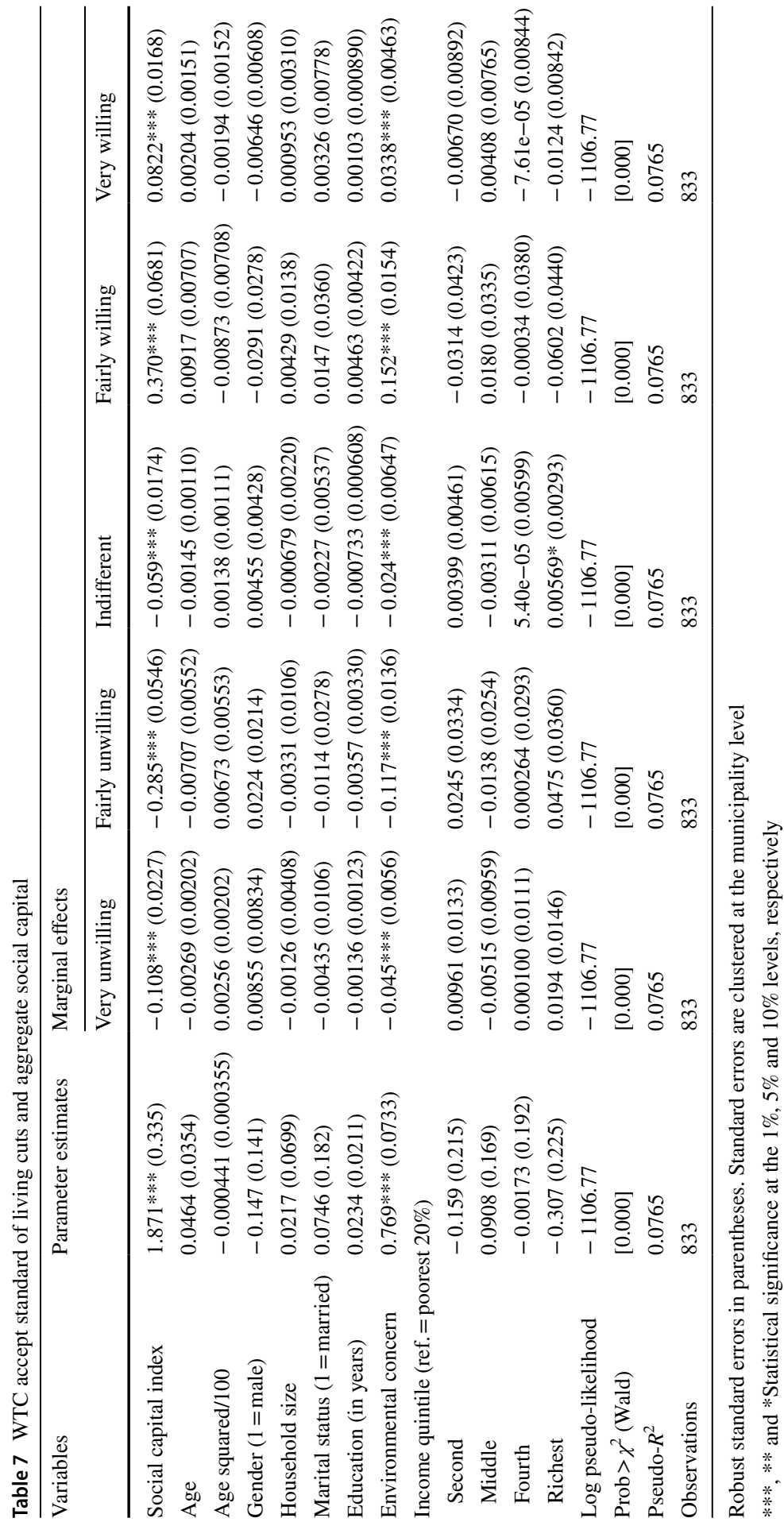


Table 8 Description of questions on social capital

\begin{tabular}{|c|c|}
\hline Variable & Questions for each construct \\
\hline Social trust & $\begin{array}{l}\text { Two item questions were used: Generalised trust is based on the question with a } \\
\text { 5-point Likert scale responses 'You can't be too careful =1' to 'Most people can } \\
\text { be trusted =5'-'Generally speaking, would you say that most people can be } \\
\text { trusted or you can't be too careful?' } \\
\text { Fairness relates to the following question with a 5-point Likert scale response rang- } \\
\text { ing from 'Most people would try to take advantage =1' to 'Most people would try } \\
\text { to be fair =5': 'Generally speaking, do you think most people would try to take } \\
\text { advantage of you if they got the chance, or would they try to be fair? }\end{array}$ \\
\hline Institutional trust & $\begin{array}{l}\text { Single item question was used with responses 'Strongly agree }=1 \text { ' to 'Strongly } \\
\text { disagree }=4 \text { ': 'Most of the time we can trust people in government to do what is } \\
\text { right' }\end{array}$ \\
\hline Civic participation & $\begin{array}{l}\text { Six items were extracted from the questionnaire with a dichotomous response scale } \\
\text { 'Yes I have =1' and 'No I have not }=0 \text { ': In the last } 5 \text { years, have you (1) 'given } \\
\text { money to an environmental group?' (2) 'taken part in a protest or demonstration } \\
\text { about an environmental issue?'; (3) 'have you taken part in a protest or demon- } \\
\text { stration about an environmental issue?'; (4) Did respondent vote in last general } \\
\text { election?). Our final measure of civic participation is at the group or membership } \\
\text { level. The questions regard whether or not respondent is (5) a member of any } \\
\text { group with the aim of preserving or protecting the environment or (6) a member } \\
\text { of a trade union }\end{array}$ \\
\hline $\begin{array}{l}\text { Social capital } \\
\text { (composite } \\
\text { index) }\end{array}$ & A composite index comprising all above questions \\
\hline
\end{tabular}

\section{References}

Bourdieu P (1986) The forms of social capital. In: Richardson JD (ed) Handbook of theory and research for the sociology of education. Greenwood Press, New York, pp 241-258

Burck J, Marten F, Bals C, Bohnenberger K (2012) The Climate Change Performance Index: Results 2012. Germanwatch and Climate Action Network Europe. http://germanwatch.org/klima/ccpi.htm. Accessed 1 Oct 2015

Burck J, Hermwille L, Krings L (2013) The Climate Change Performance Index: Results 2013. Germanwatch and Climate Action Network. http://germanwatch.org/en/5698. Accessed 1 Oct 2015

Carattini S, Baranzini A, Roca J (2015) Unconventional determinants of greenhouse gas emissions: the role of trust. Environ Policy Gov 25:243-257

Carlsson F, Johansson-Stenman O (2000) Willingness to pay for improved air quality in Sweden. Appl Econ 32:661-669

Carlsson F, Kataria M, Krupnick M, Lampi E, Lofgren A, Qin P, Sterner T (2013) The truth, the whole truth, and nothing but the truth-a multiple country test of an oath script. J Econ Behav Organ 89:105-121

Coleman JS (1990) Foundations of social theory. Belknap Press, Harvard University Press, Cambridge

Franzen A, Meyer R (2010) Environmental attitudes in cross-national perspective: a multilevel analysis of the ISSP 1993 and 2000. Eur Sociol Rev 26(2):219-234

Franzen A, Vogl D (2013) Two decades of measuring environmental attitudes: a comparative analysis of 33 countries. Glob Environ Change 23:1001-1008

Fukuyama F (1995) Trust: the social virtues and the creation of prosperity. Free Press, New York

Fukuyama F (1997) Social capital and the modern capitalist economy: creating a high trust workplace. Stern Bus Mag 4(1):4-17

Gelissen J (2007) Explaining popular support for environmental protection. Environ Behav 39(3):392-415

Halkos GE, Jones N (2012) Modeling the effect of social factors on improving biodiversity protection. Ecol Econ 78:90-99 
Hammar H, Jagers SC, Nordblom K (2009) Perceived tax evasion and the importance of trust. J SocioEcon 38:238-245

Hardin G (1968) The tragedy of the commons. Science 162(3859):1243-1248

Harring N, Jagers SC (2013) Should we trust in values? Explaining public support for pro-environmental taxes. Sustainability 5:210-227

Hsu A, Emerson J, Levy M, de Sherbinin A, Johnson L, Malik O, Schwartz J, Jaiteh M (2014) The 2014 Environmental Performance Index. Yale Center for Environmental Law and Policy, New Haven. http://www.epi.yale.edu. Accessed 19 June 2017

ISSP Research Group (2012) International Social Survey Programme: Environment III-ISSP 2010. GESIS Data Archive, Cologne, Germany. ZA5500 Data file Version 2.0.0. https://doi. org/10.4232/1.11418

Ivanova G, Tranter B (2004) Willingness to pay for the 'environment' in cross-national perspective. In: Paper presented at the Australasian Political Studies Association Conference, University of Adelaide, 29 September-1 October, 2004

Jänicke M (2005) Trend-settters in environmental policy: the character and role of pioneer countries. Eur Environ 15:129-142

Jin M (2013) Does social capital promote pro-environmental behaviors? Implications for collective governance. Int J Public Adm 36(6):397-407

Jin MH, Shriar AJ (2013) Exploring the relationship between social capital and individuals' policy preferences for environmental protection: a multinomial logistic regression analysis. J Environ Plan Policy Manag 15(3):427-446

Jones N (2010) Investigating the influence of social costs and benefits of environmental policies through social capital theory. Policy Sci 43:229-244

Jones N, Malesios C, Sophoulis CM (2008) Economic valuation of coastal water quality and protest responses: a case study in Mitilini, Greece. J Socio-Econ 37(6):2478-2491

Jones N, Malesios C, Botetzagias I (2009) The influence of social capital on willingness to pay for the environment among European citizens. Eur Soc 11(4):511-530

Jones N, Evangelinos K, Halvadakis CP, Isofides T, Sophoulis CM (2010) Social factors influencing perceptions and willingness to pay for a market-based policy aiming on solid waste management. Resour Conserv Recycl 54:533-540

Jones N, Clark JRA, Malesios C (2015) Social capital and willingness-to-pay for coastal defences in south-east England. Ecol Econ 119:74-82

Kaasa A, Parts E (2008) Individual-level determinants of social capital in Europe. Acta Sociol 51:145-168

Kollmann A, Reich J, Schneider F (2012) Who is willing to pay for the environment in the EU-an empirical analysis. EuroEconomica 31(5):15-27

Macias T, Williams K (2014) Know your neighbors, save the planet: social capital and the widening wedge of pro-environmental outcomes. Environ Behav 48:391-420

Meyer R, Liebe U (2010) Are the affluent prepared to pay for the planet? Explaining willingness to pay for public and quasi-private environmental goods in Switzerland. Popul Environ 32(1):42-65

Miller E, Buys L (2008) The impact of social capital on residential water-affecting behaviors in a drought-prone Australian community. Soc Nat Resour 21(3):244-257

Mitchell RC, Carson RT (1989) Using surveys to value public goods: the contingent valuation method. Resources for the Future, Washington

Narayan D, Cassidy MF (2001) A dimensional approach to measuring social capital: development and validation of a social capital inventory. Curr Sociol 49:59-102

OECD (2008) Handbook on constructing composite indicators: methodology and user guide. OECD, Paris

Ostrom E (1990) Governing the commons: the evolution of institutions for collective action. Cambridge University Press, New York

Ostrom E (2009) A polycentric approach for coping with climate change. Policy Research Working Paper Series, The World Bank

Ostrom E, Ahn T (2003) Foundations of social capital. Edward Elgar Publishing, Northampton

Ostrom E, Dietz T, Dolsak N, Stern PC, Stonich S, Weber EU (eds) (2002) The drama of the commons. National Academy Press, Washington

Owen AL, Videras J (2008) Trust, cooperation, and implementation of sustainability programs: the case of Local Agenda 21. Ecol Econ 68:259-272 
Polyzou E, Jones N, Evangelinos KI, Halvadakis CP (2011) Willingness to pay for drinking water quality improvement and the influence of social capital. J Socio-Econ 40:74-80

Poteete AR, Janssen MA, Ostrom E (2010) Working together: collective action, the commons, and multiple methods in practice. Princeton University Press, Princeton

Pretty J (2003) Social capital and the collective management of resources. Science 302(5652):1912-1914

Pretty J, Smith D (2003) Social capital in biodiversity conservation and management. Conserv Biol 18(3):631-638

Pretty J, Ward H (2001) Social capital and the environment. World Dev 29(2):209-227

Pretty J, Brett C, Gee D, Hine R, Mason CF, Morison JIL, Raven H, Rayment M, van der Bijl G (2000) An assessment of the total external costs of UK agriculture. Agric Syst 65(2):113-136

Putnam RD (1995) Bowling alone: America's declining social capital. J Democr 6(1):65-78

Putnam RD (2000) Bowling alone: the collapse and revival of American community. Simon and Schuster, New York

Putnam RD, Leonardi R, Nanetti RY (1993) Making democracy work: civic traditions in modern Italy. Princeton University Press, Princeton

Rupasingha A, Goetz J, Freshwater D (2000) Social capital and economic growth: a county-level analysis. J Agric Appl Econ 32(3):565-572

Singleton S, Taylor M (1992) Common property, collective action and community. J Theor Polit 4(3):309-324

Torgler B, García-Valiñas MA (2007) The determinants of individuals' attitudes towards preventing environmental damage. Ecol Econ 63:536-552

van Oorschot W, Arts W, Gelissen J (2006) Social capital in Europe. Measurement and social and regional distribution of a multifaceted phenomenon. Acta Sociol 49:149-176

Whitehead JC (1991) Environmental interest group behaviour and self-selection bias in contingent mail surveys. Growth Change 22(1):10-21

Woolcock M (1998) Social capital and economic development: toward a theoretical synthesis and policy framework. Theory Soc 27:151-208

Yogo UT (2015) Trust and the willingness to contribute to environmental goods in selected African countries. Environ Dev Econ 20(5):650-672

You J-S (2012) Social trust: fairness matters more than homogeneity. Polit Psychol 33(5):701-721

Publisher's Note Springer Nature remains neutral with regard to jurisdictional claims in published maps and institutional affiliations. 